\section{Distopía, eutopía y crisis social en el cine mainstream (los casos de Los juegos del hambre y Del revés)}

Dystopia, eutopia and social crisis in mainstream cinema (the cases of The Hunger Games and Inside Out)

\section{Antonio MÉndez-Rubio* Ana-Clara Rey-Segovia*}

\begin{abstract}
Resumen
En el marco de un mundo globalizado, la aparente "desideologización" que acompaña a los bienes culturales actuales, sirve a los propósitos de reproducción del sistema capitalista, entendido este dentro de su vertiente cultural actual como un sistema omnipresente y omniabarcante. En este sentido, los productos culturales del mainstream estadounidense, continúan constituyendo, aún a día de hoy, uno de los principales pilares a

Universitat de València, Blasco Ibáñez, 32 / 46010 Valencia (España). Correo electrónico: antonio.mendez@uv.es

** Universitat de València, Blasco lbáñez, 32 / 46010 Valencia (España). Correo electrónico: a.clara.rey@uv.es
\end{abstract}

través de los cuales el sistema se representa a sí mismo, proponiendo y defendiendo determinados modos de vida, en concreto, el American Way of Life. En el actual contexto, el mainstream cinematográfico, a través de productos como "Los Juegos del Hambre" (The Hunger Games, Ross, 2012; Lawrence, 2013, 2014, 2015) o "Del Revés" (Inside Out, Docter, 2015), apuestan por una aparente doble vía de falsa salida (distópica y eutópica), ante los conflictos de orden psicológico y/o ideológico que atraviesan la crisis del modelo social actual.

Palabras clave: crisis, capitalismo, mainstream, eutopía, distopía

\begin{abstract}
Within the context of a globalized world, the seeming "de-ideologization" that accompanies contemporary cultural products is in fact useful to the reproduction of the capitalist system, this being an omnipresent and over-encompassing system. With that in mind, American mainstream cultural industry is one of the main pillars through which the system represents itself, proposing and defending specific worldviews, namely, the American Way of Life. Recent mainstream cinema, through products such as The Hunger Games (Ross, 2012; Lawrence, 2013, 2014, 2015) or Inside Out (Docter, 2015), proposes an apparent "two-track" strategy of a false wayout (dystopic and eutopic), as a way to face the psychological and/or ideological conflicts that characterize the crisis of the contemporary social model.
\end{abstract}

Key words: crisis, capitalism, mainstream, eutopia, dystopia 


\section{Planteamiento inicial}

El cine, y en concreto el cine mainstream, constituye un pilarfundamental en las estructuras culturales, pero también sociales y económicas a través de las cuales el sistema capitalista se representa a sí mismo. Entendiendo el mainstream como la corriente de representación dominante dentro delaindustriacinematográfica, la referencia a Hollywood se vuelve inevitable. En el contexto de un mundo globalizado, la industria cultural estadounidense parece ocupar un papel central en la conformación de imaginarios colectivos a escala mundial. Imaginarios que, al fin y al cabo, constituyen el sistema axiológico que propone formas de vida concretas. El denominado American Way of Life, conformaría así una visión del mundo o una fuente de sujeción que, siguiendo los cauces de la globalización, habría transgredido la totalidad de las fronteras culturales. Así, los formatos, técnica y la estética que acompañan a este tipo de representación masiva han proliferado a través del mercado global, generando un movimiento homogeneizador en el que la cultura popular, arraigada en las raíces históricas de las sociedades, ha dejado de tener un papel hegemónico en la construcción de identidades colectivas en favor de una cultura popular-masiva cada vez más dependiente de los intereses comerciales.

Teniendo esto en cuenta, la importancia del estudio del cine mainstream estadounidense se hace evidente. El estudio de casos fílmicos como Los juegos del hambre (2013) o Del revés (2015) ha sido abordado en trabajos previos de forma preliminar y tentativa (Méndez-Rubio, 2016; Rey Segovia, 2016) y se trata en este artículo como centro de un foco analítico más amplio y contrastado. En el marco de lo que
Zizek (2009) denominaría "capitalismo cultural", el cine hollywoodense constituiría un elemento de mediación y conformación del sujeto a través del consumo de un tipo de bienes culturales aparentemente desideologizados que, sin embargo, tendrían un papel fundamental en la reproducción social del sistema. En este sentido, el análisis crítico de los textos fílmicos debería realizarse en contraste con el contexto actual de crisis de la subjetividad en relación con el sustrato ideológico, socioeconómico y político que representa la vida en común.

El calificativo mainstream se entendería, pues, como un modo de entender el cine más abiertamente subsumido en la dinámica de las industrias culturales globales. Es decir, se trata de un calificativo que puede ser de ayuda "para descifrar el entertainment y la cultura de masas en Estados Unidos -o sea, en el mundo" (Martel 2011: 42). Se podría asimilar esta acepción del término mainstream a la consideración de lo masivo (producido y difundido "desde arriba") frente a (y en negociación con) lo popular ("desde abajo") tal como ha sido defendida por MartínBarbero (2010). El análisis crítico de los textos fílmicos se vuelve necesario especialmente en contextos de crisis, y esto tanto en relación con el espacio social, como tomados en tanto formas espaciales que condicionan la construcción social de la realidad. La consideración crítica de la cultura popular-masiva, cuando se la sitúa en una clave socioespacial, contribuye a una comprensión decisiva del mundo real ya que, al tratar estos componentes de la comunicación social, "se trata, después de todo, del marco de la vida" (Lefebvre 2013: 147).

En los últimos tiempos, de entrada, el género de la distopía ha copado buena parte de la producción cinematográfica mainstream, tanto 
en Estados Unidos como en el resto del mundo. La preferencia por este género como modo de expresión de un temoro descontento compartido en la sociedad es un suceso recurrente en la historia del capitalismo, en el que las crisis se constituyen como momentos cíclicos, y traumáticos, en los que se visibilizan las costuras del sistema, sus contradicciones. Desde la que podríamos considerar como película inaugural del género distópico, Metrópolis (Lang, 1927), pasando por el ciberpunk de los años ochenta con Blade Runner (Scott, 1982), hasta las actuales distopías adolescentes como la saga de Los Juegos del Hambre (Ross, 2012; Lawrence, 2013; 2014; 2015), podemos detectar, más explícita o implícitamente, los movimientos de apertura crítica hacia distintos elementos negativos intrínsecos a las lógicas del sistema institucional.

De forma elocuente esta cuestión se conecta con la problemática de las relaciones entre ideología y utopía. Esta relación, como ha planteado Ricoeur (2009), ha tendido a reducir el segundo polo al poder del primero, de lo cual ha resultado un empobrecimiento del primero al quedar así reducido a una clave unidireccional, autosuficiente. En un plano psicológico e ideológico, tal como había señalado Mannheim (1992: 112): "el término utópico se puede utilizar para todos aquellos procesos mentales que no reciben sus impulsos directamente de la realidad social, sino que los perciben de imágenes, manifestadas en símbolos, fantasías, sueños, ideas y similares". Desde luego, existe una muy larga tradición de ficciones literarias que han elaborado la cuestión utópica/distópica, desde T. Moro (Utopía, 1516 [2016]) o T. Campanella (Ciudad del sol, 1602 [2018]) hasta A. Huxley (Un mundo feliz, 1932) o G. Orwell $(1984,1949)$, pasando por H. G. Wells (Una utopía moderna,
1905) o Y. Zamiatin (Nosotros, 1921), entre muchos otros. Sin embargo, nos interesa aquí apoyar la argumentación en consideraciones sociológicas y filosóficas de esta problemática dado que puede así comprenderse más directamente el objeto de discusión. En esta línea, por ejemplo, sería fundamental recuperar la perspectiva dialéctica de la Teoría Crítica tal como la concibiera la Escuela de Frankfurt a lo largo del siglo XX. En esta trayectoria es básica la premisa de M. Horkheimer según la cual la utopía no solamente se reduce a proponer un mundo alternativo sino que, en su raíz epistemológica y política, la utopía "representa la crítica de lo existente. Su importancia estriba en cómo, partiendo del análisis de anhelos particulares, se puede llegar a una situación real" (Horkheimer 1992: 127).

En otras palabras, si algo resulta valioso en el juego de relaciones entre lo ideológico y lo utópico sería cómo este juego condiciona nuestra mirada, nos ayuda a comprender la realidad como una construcción móvil, paradójica, atravesada por tensiones que se instauran (conscientemente o no) en las prácticas y discursos sociales. La utopía, tomada en su tensión polar entre eutopía y distopía, y en la medida en que no se limita a lo existente, pone a distancia el sistema cultural y social y nos recuerda que lo real puede ser extrañado, transformado, ya que "no hay integración social sin subversión social” (Ricoeur 2009: 58). De ahí que el imaginario utópico resulte una pieza clave para la reproducción y también para la crítica de la realidad social y los códigos simbólicoideológicos que la legitiman. Por supuesto: este marco interpretativo requiere una consideración caleidoscópica, lo más amplia posible, tanto en lo referente al concepto de utopía (AAVV 1992; Claeys y Tower 1999) como al de distopía 
(Claeys 2017; Bauman 2017). Aun así, se intenta aquí extraer el núcleo de la cuestión crítica que afecta a estos debates: la utopía abre un espacio no-existente de representación y vivencia de la realidad que, no obstante, afecta a través de la dimensión simbólica tanto las percepciones como las acciones de individuos y grupos. Por esta razón la problemática utópica cumple una función ideológica y sociopolítica de primer orden en cualquier contexto histórico.

La ficción utópica, por ejemplo, en el terreno de la ciencia-ficción, puede ayudar a denunciar aspectos concretos de la realidad dominante. Sin embargo, el cierre del espacio ideológico promovido por las grandes industrias culturales, y que acompaña el fin de los grandes relatos utópicos, tendería a anular la crítica en pos de un cinismo en el que el sujeto es incapaz de relacionar su malestar con el funcionamiento del sistema del que es partícipe. La eutopía funciona entonces como una idealización paralizante, de signo positivo, pero complementaria de la parálisis conformista inducida por la distopía de masas. Ésta es la hipótesis básica que aquí se defiende y articula. En este sentido, consideramos que el análisis de las representaciones cinematográficas eutópicas y distópicas hollywoodenses contemporáneas, puede aportarnos algunas claves para comprender cómo estas películas, aun cuando expresan de forma explícita o implícita la denuncia de las lógicas sistémicas que rigen nuestro presente, siguen, sin embargo, siendo incapaces de pensar la historia pasada y las posibilidades de futuro más allá del modo de producción capitalista. El sistema opera así en la esfera cultural del imaginario de masa. Este plano de la vida social es así instrumentalizado de manera que las distopías y las eutopías pasan a ser un síntoma de malestar, una muestra de pesimismo ante la condición humana o, en el mejor de los casos, un mecanismo idealizado de denuncia, pero nunca se atisban alternativas reflexivas o en cierto modo propositivas.

Así, los textos fílmicos enmarcados dentro de estos géneros distópicos/eutópicos participarían de esta operación de borrado o de desaparición de la alteridad propia de la cultura masiva. La realidad se totaliza así como imperativo de hegemonía, haciendo desaparecer todo exterior mediante la institucionalización y naturalización de la hegemonía de la cultura masiva. En el caso de los productos audiovisuales, la omisión, al menos explícita, de la ideología, parece un prerrequisito para que éstos alcancen una dimensión mainstream que, por otro lado, sigue siendo la aspiración evidente de un producto cultural que opera como una mercancía. Dicho de otra manera, esta ideología de la noideología, en nuestra época, encuentra uno de sus principales apoyos en la cultura masiva $\mathrm{y}$, más específicamente, en los medios de comunicación masivos.

Para dar cuenta de cómo analizar un texto fílmico a fin de entenderlo como índice de una situación social, se hace preciso poner el foco en las condiciones ideológicas que resultan dominantes en la sociedad contemporánea. Se trata así de evidenciar algunos resortes de la ideología que se esconde, de manera eficaz, en las representaciones más reconocibles del cine mainstream. Ante la ya mencionada hipótesis sobre el cierre ideológico y su plasmación en un sentimiento de carencia de alternativas, por ejemplo, Los Juegos del Hambre nos propone una lectura del mundo en clave de necesidad de refundación del mundo en términos nacionales o civilizatorios, eufemismos que salvaguardan al capitalismo de una alusión directa. En un 
contexto de crisis social, económica y política, la falta de expectativas aparece representada en el film a través de una juventud que se ve obligada a competir a muerte para sobrevivir. Por su lado, Del revés (Inside Out, Docter, 2015) funciona como exploración del circuito emocional del cerebro infantil y sus posibilidades de adaptación y normalización dentro de la coyuntura social del momento presente. El tratamiento eutópico y eufórico se asocia aquí al colorismo de los dibujos de animación para articular una historia cotidiana envuelta en el efectismo espectacular característico de la factoría Disney. De esta forma, la vida diaria en una ciudad de Estados Unidos (San Francisco) adopta una tensión psicológica que, como sucede convencionalmente, se resuelve felizmente.

\section{La estrategia distópica: Los juegos del hambre (G. Ross / F. Lawrence, Lionsgate, 2012-2105)}

La saga de Los Juegos del Hambre nos plantea un mundo post-apocalíptico, centrado en la nación de Panem. La misma se divide en trece distritos más el Capitolio, donde se concentra el poder político y económico. Tras una rebelión fallida, se instauran -como castigo y recordatorio de la misma- los denominados "Juegos del Hambre", una competición en la que veinticuatro jóvenes de entre 12 y 18 años, doce hombres y doce mujeres, luchan a muerte. Los juegos, así como la vida de los tributos elegidos, son retransmitidos a toda la población de Panem en forma de reality show a través de la televisión del Capitolio. En la celebración de los $74^{\circ}$ Juegos del Hambre, Katniss, una chica procedente del distrito minero número 12, desafiará las reglas de los Juegos proclamándose como vencedora e iniciando una rebelión contra el Presidente Snow, líder de Panem.
En Los Juegos del Hambre, el recurso a los elementos característicos de la Antigüedad Clásica, unido al mito fundacional de los Estados Unidos, parece estar estableciendo un paralelismo en el que el país norteamericano se identificaría con la civilización, encarnada a su vez en la nación de Panem. Teniendo en cuenta el contexto sociohistórico de crisis en que el film nace, podríamos deducir que una de sus posibles lecturas estaría relacionada con la necesidad de una refundación sobre los pilares fundamentales del Estado moderno, esto es, con la idea de democracia liberal como mejor opción posible frente a la opresión y/o el totalitarismo.

Esta idea de democracia liberal está, sin duda, ligada también a la idea de un retorno a los postulados de progreso y libertad, propios de la modernidad. La presentación de la modernidad como un proceso aún pendiente (Habermas 2008), contrasta por otro lado con el planteamiento postmoderno del film, que nos sitúa en un futuro post-ideológico en el que tanto la Historia en mayúsculas como la historia en minúsculas, no se presenta como un elemento explicativo de los problemas presentes, sino tan sólo como un cúmulo de clichés que sirven para reforzar la idea del liberalismo como única vía de salida frente a la barbarie.

La hipervisibilización del fascismo clásico que ofrece la saga colabora a este propósito afirmativo, marcando claros contrastes entre algunos elementos fácilmente reconocibles de los totalitarismos del siglo XX, y aquellos escenarios o personajes que encarnan las máximas del progreso y la modernidad. De esta forma, mientras la bandera del Panem autoritario presidido por el despiadado Snow presenta claras similitudes con la bandera 
de la Unión Soviética, la bandera del "nuevo" Panem de la Presidenta Coin recuerda a la de la Unión Europea, así como también a una de las variantes de la primera bandera de los Estados Unidos, que presentaba trece estrellas blancas en círculo en representación de las trece colonias originales que se independizaron de Reino Unido. Ambas banderas son visibles durante toda la tetralogía fílmica, como se puede observar en las siguientes imágenes:

Imagen 1. Presidente Snow y banderas de Panem

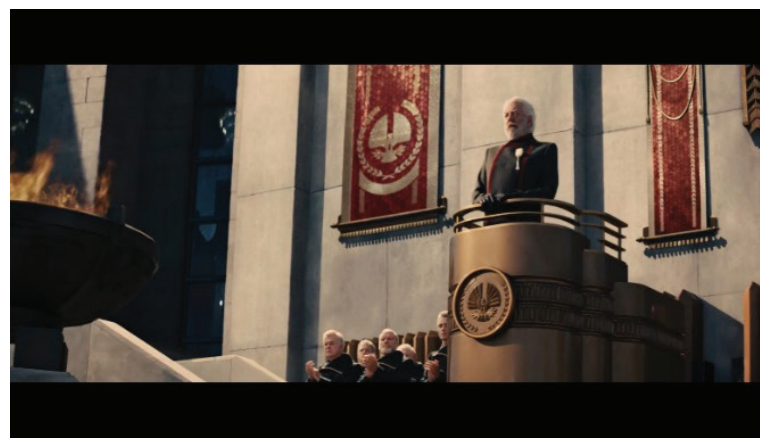

Fuente: The Hunger Games. Catching Fire

(Lawrence, 2012)

Imagen 2. Presidenta Coin y bandera del Nuevo Panem

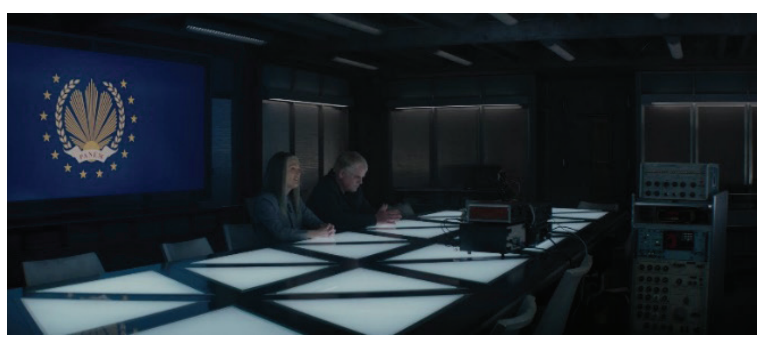

Fuente: The Hunger Games. Mockingjay Part 2. (Lawrence, 2015)
Como se puede observar en la imagen 1, no sólo la bandera remite al recuerdo de los totalitarismos del siglo $\mathrm{XX}$, sino también la composición espacial del plano recuerda a las conocidas imágenes procedentes de filmes como Olympia (1938) o "El triunfo de la voluntad" (Triumph des Willens, 1935), ambos de Leni Riefenstahl, en los que se muestra a A. Hitler pronunciando un apasionado discurso político ante la masa:

Imagen 3. Escena del documental de Riefenstahl

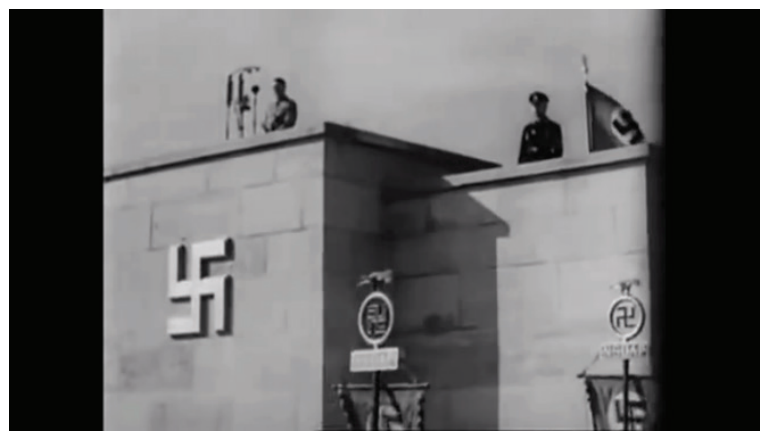

Fuente: Triumph des Willens (Riefenstahl, 1935)

Katniss, la protagonista de la revolución y de la propia película, concentra las expectativas tanto del espectador real como del ciudadano revolucionario que observa la rebelión desde su distrito. Cuando la rebelde Presidenta Coin habla del "Nuevo Panem", habla de refundación: es el mito de la barbarie pre-social moralmente edificante (Bauman 2015) sobre el cual se crean y asientan las democracias modernas. La sobrerrepresentación del totalitarismo clásico, del fascismo moderno (Bauman 2015) como enemigo a batir, funcionaría de nuevo como elemento legitimador del paradigma hobbesiano, sobre el cual se justificaría la 
necesidad común de (re)fundar el proceso civilizatorio.

Desde esta perspectiva, la representación del skyline de la capital de Panem como una urbe moderna de primer mundo, armoniosa estéticamente, funciona como una metáfora y al mismo tiempo una crítica a la consolidación utópica de la civilización.

Imagen 4. Skyline de Panem

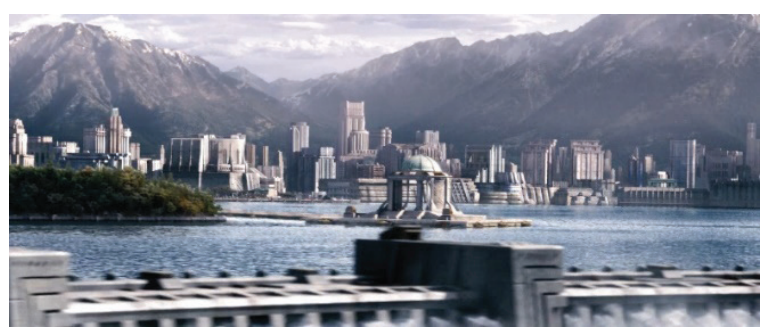

Fuente: The Hunger Games (Ross, 2012)

Se trata de una especie de balneario donde, al contrario que en los distritos, el trabajo asalariado y las actividades económicas no encuentran sitio en el espacio social, que parece reservado al libre albedrío y el consumo desenfrenado, opulento, de sus habitantes. La imagen de los habitantes del Capitolio, atractivos, ociosos y sofisticados, contrasta con el plano que minutos antes nos enseñaba a los obreros del Distrito 12 , dirigiéndose cabizbajos a la mina, siguiendo el estricto orden que requiere el trabajo en la era industrial.
Imagen 5. Obreros del Distrito 12 de Panem

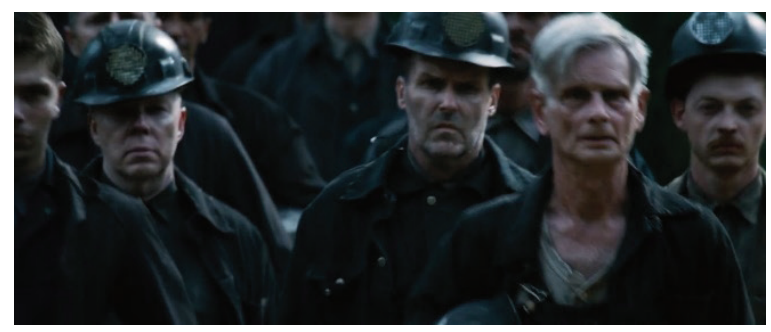

Fuente: The Hunger Games (Ross, 2012)

Imagen 6. Ciudadanos del Capitolio

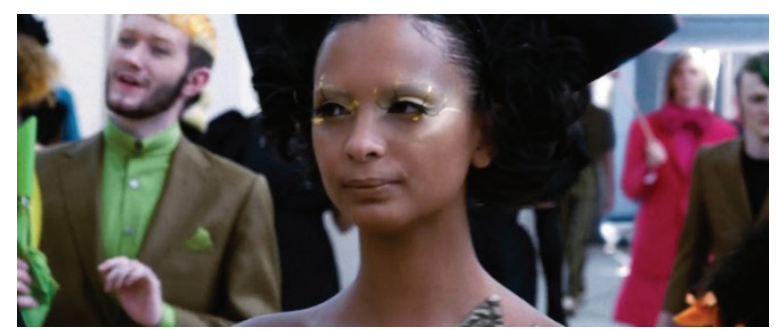

Fuente: The Hunger Games (Ross, 2012)

El énfasis tan marcado en los contrastes escénicos y sociales acabará respondiendo (cuando se plantee el desenlace final) a la reafirmación de las democracias liberales, que al ser comparadas con los períodos de oscuridad y desde una concepción pesimista sobre la condición humana, se constituye como única posibilidad de progreso y de vida en sociedad. El relato que se representa en el film es, por tanto, el de la necesidad de un Leviatán que controle las pasiones naturales de los hombres que, según las palabras del personaje de Plutarch, asesor primero del dictador Snow y devenido más tarde en consejero de los rebeldes, son "débiles y estúpidos" con "un gran talento para la autodestrucción". 
En cuanto a la organización del espacio fílmico, éste se plantea como una estructura cerrada donde los límites son impuestos tanto en la estructura narrativa, ficcional, como en el escenario representado. Los límites de la representación son los límites de Panem, es decir, que todas las posibilidades de cambio o de opresión nacen en los límites de este mundo, que se identifica con la nación. Esto podría, otra vez, asimilarse a la cultura aislacionista en buena parte de la tradición de los Estados Unidos. La representación se irá clausurando de forma que la nación de Panem funciona como una metáfora para relatar, para reflejar indirectamente no sólo la situación de los Estados Unidos, sino del mundo entero en la modernidad avanzada.

Así, nos encontramos con el interior del distrito o el interior del hogar, mientras el único espacio aparentemente exterior lo representa el bosque: un exterior imposible, inalcanzable, un nolugar utópico para los jóvenes personajes. Lo mismo sucederá a lo largo de todas las películas que componen la saga: los espacios exteriores representan el peligro, la inseguridad o la imposibilidad. Incluso el espacio exterior donde se realizan los Juegos, como ya hemos señalado, se trata de un exterior controlado, virtualmente creado por y para el Capitolio.

El exterior del Distrito es donde Katniss caza para sobrevivir, donde parece sentirse cómoda y segura. Sin embargo, se trata de un exterior que tan sólo representa una huida momentánea, imposible, como se puede extraer de la conversación que la protagonista mantiene con su amigo Gale. En el diálogo, Gale le propone a Katniss la posibilidad de huir al bosque, a lo que Katniss responde que eso no lo conseguirían y que deben quedarse para cuidar de sus familias. Gale insiste aunque, al final de la conversación, acaba aceptando esa imposibilidad. La alternativa de una rebelión no existe en la mente de los personajes, el exterior no representa una solución para ellos. El bosque representaría, entonces, un "falso exterior" (Méndez-Rubio 2016: 33) o lo que Sloterdijk (2007) calificaría como un pliegue más del "Gran Interior". La exterioridad serviría, en definitiva, para reforzar "las claves ideológicas de ese interior ya dado como inamovible, o normal, o natural" (MéndezRubio 2016: 35).

En este sentido, la saga representa la imposibilidad de un futuro fuera de los límites impuestos por el poder. El futuro se plantea como un retorno al pasado, como la vuelta de los valores de la modernidad sobre la base de la necesidad de completar el pendiente proceso civilizatorio. Como diría Bauman (2015: 34), se trataría de que aún necesitamos "más civilización" como base para superar el problema hobbesiano sobre la condición humana que, en caso de no resolverse, podría conducirnos a un nuevo Holocausto. Así, la narración se apoya en ciertos mecanismos narrativos o clichés, tales como el amor romántico, la institución familiar, complementándolos con la idea de rebelión, libertad o igualdad, como bases de un relato que, en momentos de crisis como el actual, parecen volverse una necesidad para un público juvenil que se percibe desesperanzado, desorientado y carente de futuro.

Sin embargo, la visión pesimista sobre la condición humana que personajes como el de Plutarch plasman claramente en el film, viene a reafirmar ante el espectador esta visión desideologizada de la realidad social (o, por el contrario, completamente integrada dentro la ideología dominante), en la que la alternativa pragmática y madura se identifica con la "amarga 
realidad capitalista como el mejor (o el menos malo) de todos los mundos posibles" (Zizek 2009: 32). En ese sentido, la progresiva desaparición del exterior, representada en el espacio fílmico a través de la totalización del espacio en un "gran interior", sirve a la reproducción de la ideología dominante en el sentido de que refuerza la dicotomía entre civilización y barbarie. En otras palabras, si la globalización se ha interpretado como una 'sociedad indoor' o 'gran interior' (Sloterdijk 2007) de aquí se puede deducir que el exterior sigue no solamente existiendo sino existiendo de una forma negada o espectral, como bien se está aprendiendo a través de la tragedia migratoria a principios del siglo XXI, la intemperie de multitudes buscando refugio o asilo, o en las nuevas formas de pobreza y precariedad que la legalidad permite y genera. Por 'desaparición del exterior' habría entonces que entender no un exterior finalmente eliminado o superado sino convertido en una amenaza ambiental o espectral, en un lugar de violencia y muerte cada vez más invisible por ser cada vez más inminente. Dentro y fuera, vistos así, no solamente no han disuelto sino que han reafirmado su frontera como una frontera de conflicto y de sufrimiento colectivos.

La saga -inscrita dentro de lo que se puede considerar como cinematografía mainstreamfunciona en forma de borrado o reetiquetado de las demandas populares nacidas tras la crisis financiera de 2008. Sobre la base de la posibilidad de consolidación distópica de nuestro presente, la tetralogía Los Juegos del Hambre nos propone una lectura pesimista en la que la única alternativa a la realidad establecida es un retorno al pasado o, dicho de otra forma, un cierre del sistema sobre sí mismo: es decir, que no hay alternativa. Así, las denuncias de los movimientos sociales surgidos durante la reciente crisis (bajo lemas como "iLo llaman democracia y no lo es!" Del $15 \mathrm{M}$ o el "We are the 99\%" de Occupy Wall Street) son vaciadas y resignificadas en una propuesta pragmática de carácter cínico que entiende que no existe alternativa real fuera del capitalismo. De esta forma, estos postulados se vuelven inofensivos de cara a un espectador inmerso por completo en la ideología hegemónica ya que, como indica Zizek (2008: 19): “Cualquier universalidad que se pretenda hegemónica debe incorporar al menos dos componentes específicos: el contenido popular «auténtico» y la «deformación» que del mismo producen las relaciones de dominación y explotación".

Así pues, Katniss, la protagonista, así como la cohorte de jóvenes que le acompañan durante buena parte de la tetralogía, representarían en el film ese lado rebelde que acompaña al individuo joven en el imaginario colectivo. Desde esta perspectiva de infantilización de las expectativas de futuro intrínsecas a dicha condición podríamos, como hipótesis interpretativa, establecer un paralelismo con la realidad. $Y$ es que, una buena parte del consumidor habitual de este tipo de productos culturales representa el germen real de la reproducción social del propio capitalismo. Como portaestandartes de la ideología de la no-ideología, rehúyen constantemente de cualquier idea utópica y proyecto de transformación del futuro.

En este sentido, como apunta Zizek (2009: 23), "las crisis sacuden la autocomplacencia de la gente" sin llegar a poner en riesgo "las premisas básicas de la ideología dominante" que, muy por el contrario, acaban saliendo reforzadas y "reafirmadas más violentamente". La incredulidad con respecto a los metarrelatos (Lyotard 2000: 10) que acompañó al nacimiento 
de las nuevas generaciones de jóvenes, hoy consumidores de los productos de la cultura de masas global, viene representado en los filmes por el blindaje del statu quo que implica la, finalmente, traicionada revolución. Traición que condena a los protagonistas a renunciar a su voluntad de transformación del orden vigente a cambio de un proceso de renovación de las élites y de alteración superficial del espacio simbólico, cuestión que acaba por confirmar el cierre del espacio ideológico.

De esta manera, los filmes esconden la paradoja del joven descontento, heredero de aquel "espíritu del 68" (Milner 2010: 177) recuperado en la actualidad por los movimientos juveniles críticos con el sistema político, como los ya mencionados Occupy o el 15M. Joven que, en definitiva, critica y desea el capitalismo a partes iguales, pero que debido a su construcción como sujeto inmerso en este proceso de cierre ideológico y, por tanto, ausente de cualquier sentido de proyección utópica, se ve abocado a hacer uso de las únicas categorías en las que es capaz de entenderse como ser libre; esto es, en el seno de una democracia liberal de tipo belicista, capaz de hacer frente a la otredad amenazante (Bauman 2009: 77), o incluso terrorista, que acompaña toda democracia. Este "cierre sofocante" (Zizek 2008: 40) del espacio de lo posible, acaba limitando su capacidad de actuar sobre la realidad, convirtiendo la crisis en un estado permanente, en una constante "fuga hacia adelante" (López Petit 2009: 40).

La energía de esa supuesta juventud crítica con el sistema se trasladaría al film junto a la serie de demandas políticas que han surgido a partir de la Crisis de 2008. Unas demandas que, aunque se representen con la estética de la revolución en la saga de Los Juegos del
Hambre, no serían en estas películas más que la necesidad de esta parte de la población, la juventud, de cara a integrarse en el sistema, para huir de los márgenes del mismo o, dicho de otra manera, para alcanzar supuestamente la condición plena de ciudadanía.

\section{La estrategia eutópica: Del revés (P. Docter, Disney/Pixar, 2015)}

Inside Out (Del revés) se presenta como una aventura vivida desde el interior del cerebro de su protagonista, Riley, una niña de once años cuya vida se ve agitada por la mudanza de sus padres desde Minnesota hasta San Francisco. Las vivencias mentales de Riley son escenificadas mediante el recurso a cinco personajes, que a su vez encarnan cinco emociones básicas: Asco, Ira, Miedo, Tristeza y Alegría, ésta última liderará al grupo y llevará en todo momento la voz principal a la hora de orientar las distintas peripecias que vive la protagonista. La película se presenta así para el público global como (según la nota de contraportada en la carátula) "la película más emocionante. Disfruta de esta divertida y conmovedora historia que la revista Rolling Stone ha calificado como una completa obra maestra". La atención a los detalles de marketing se hace explícita en la comercialización publicitaria del film junto con detalles como la voz de Rihanna, la participación musical de Jennifer Lopez, el corto animado Lava, o la asesoría acreditada del Mortimer B. Zuckerman Mind Brain Behavior Institute, entre otros.

A pesar de que en varios momentos del guión se experimentan sensaciones inquietantes y de pesadumbre, la historia está regida desde principio a fin por el eje motivador que representa 
Alegría, que se refleja en el personaje de Riley como un espejo. Así, su padre le confiesa: "eres la viva imagen de la alegría", o se reconoce abiertamente que "los recuerdos de Riley son en su mayoría alegres". Ya las imágenes promocionales de Del revés, en la línea de otros estrenos de animación recientes, como Home (Dreamworks/20th Century Fox, 2015), es una declaración abierta de intenciones en el sentido de la condición eufórica o eutópica de su mensaje:

Imagen 7. Personajes de Inside Out

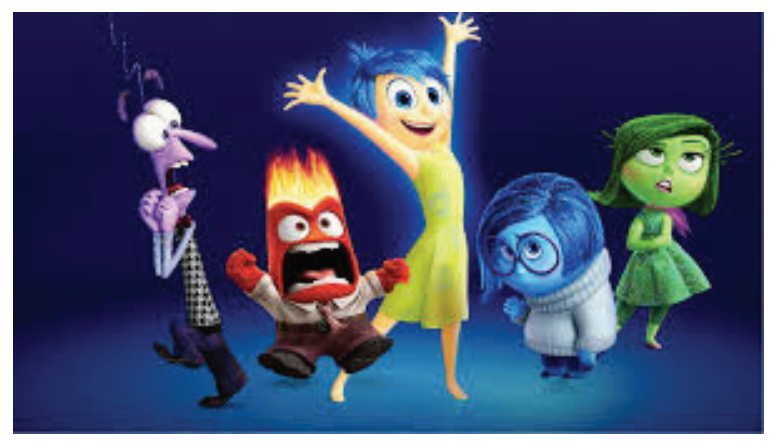

Fuente: Inside Out (Del revés, 2015)

Imagen 8. Personajes de Home

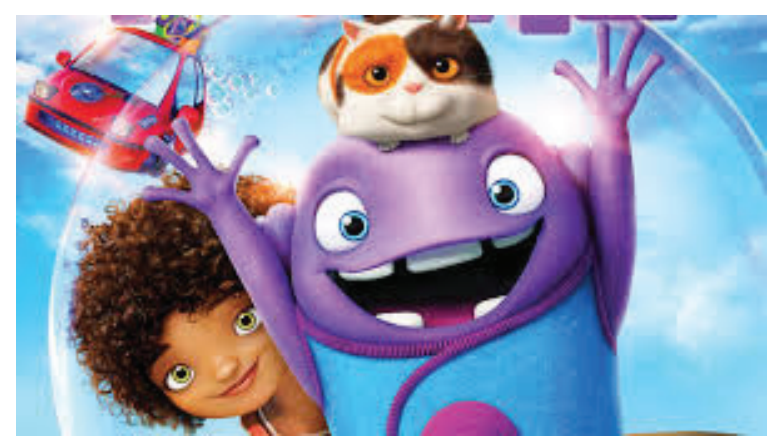

Fuente: Home (Hogar dulce hogar, 2015)
Cuando, por ejemplo, el personaje de papá parece excesivamente preocupado por motivos laborales y financieros, una y otra vez se repiten frases del tipo: “ipodría ser peor!", "ipensemos en las cosas buenas!" o "ivamos a tener un buen día, un buen año y una buena vida!". De esta forma, las experiencias de angustia asociadas a la crisis vital de la pre-adolescente Riley se afrontan en todo momento desde la clave de una especie de terapia anti-crisis cuyo lema rezaría: estar-feliz-pase-lo-que-pase.

El estrés y las tensiones propias de la mudanza de ciudad y los apuros familiares se explicitan en el film como una "crisis nerviosa" provocada por el excesivo "peso de los problemas". No en vano, Alegría ejerce de terapeuta con Tristeza al recomendarle "manuales mentales" y que así la conciencia (representada como una suerte de torre panóptica que preside una central industrial) pueda restaurar lo antes posible su misión de autocontrol y ordenamiento de la acción. Este predominio escenográfico y narrativo de la conciencia se establece en la película a pesar de que, desde un enfoque cognitivo, se sabe que "la consciencia ignora un noventa y nueve por ciento de la entrada de datos sensorial (...), no es más que una ilusión de perspectiva" (Zizek 2006: 59). La contrapartida en la historia de este rol predominante de la conciencia es entonces, por lógica, la representación del subconsciente como un sótano oscuro y siniestro, pues es allí "adonde llevan a los que dan problemas".

El inconsciente, por tanto, se muestra como aquello que es necesario combatir ya que, como exclama Alegría, "¡Ahora Riley necesita ser feliz!", y su derrumbamiento emocional y personal ha de ser superado en virtud de la fuerza que se desprende de sus deseos y sus sueños. Sin embargo, estos deseos son 
certeramente perfilados cuando sabemos que su canción favorita no es otra que la melodía del jingle publicitario del anuncio de chicle Tripe Dent. Por mucho que los avatares "fuera de la Central" pongan en peligro a los personajes y, en consecuencia, a Riley, no obstante, el principio de realidad se mantiene incólume y con la firmeza suficiente como para salvar los terrores de "la estación de la abstracción" (donde la angustia se expresa al saberse angustiosamente "no figurativos"). Es ese principio de realidad el que encaja por tanto con los deseos de Riley, ya que sus deseos (por ejemplo, la fascinación por la publicidad y el espectáculo) coinciden de pleno con la realidad tal como viene establecida en los tiempos del capitalismo mundializado del siglo XXI. No hay, por tanto, exterior, sino solamente desvíos o episodios fugaces que provocan la experiencia de crisis en el sujeto, pero que rápidamente son solventados por la acción preponderante, dotada de un heroísmo idealizado, sublimado, que se identifica por convención con la felicidad.

Esta emoción de felicidad, en suma, dado su enfoque conformista, no lleva al sujeto a intervenir en sus condiciones de vida para modificarlas o transformarlas en la práctica, sino que más bien contribuye de forma salvífica a que la adaptación a las convenciones de la realidad familiar, escolar y social se produzca del modo más suave y eficaz posible. En este punto, resultan nítidas las correlaciones entre el espacio subjetivo y social (conciencia y fantasía / casa familiar / colegio y calle) y la topología de la psique delineada por la investigación psicoanalítica. En este sentido, desde Freud (2017), la subjetividad se entiende desde una hipótesis dotada de una "representación espacial, tópica" (2017: 17) que funciona por un proceso de estratificación de tres dimensiones elementales: a) la conciencia del Yo, que actúa de hecho como "superficie perceptora" (2017: 17); b) la dimensión subconsciente (Ello) que queda protegida y a la vez sometida por (debajo de) la función del Yo; c) el Superyo o "ideal del yo" (2017: 35) que se sobrepone al Yo para que éste sea reconocido y adquiera existencia social en el plano simbólico de la vida colectiva. Pues bien, volviendo al film que nos ocupa, podría trazarse una correlación homológica entre colegio-calle y Superyo, fantasía-imaginación y Ello, hogar-familia y Yo. Las presiones tanto "desde arriba" (superyoicas) como "desde abajo" (inconscientes) se resolverían con un equilibrio compensatorio que se concentra en los valores propios de la familia norteamericana de clase media. Se confirmaría así el argumento freudiano al respecto de estudiar la subjetividad sin "abandonar nunca una valoración ética y social” (Freud 2017: 25).

Por así decirlo, ambas espacialidades, la que podría llamarse de forma aproximada exterior y la más interior, quedan engarzadas por sentimientos que se emplazan en cada una de ellas: emoción / seguridad / opresión. Como se puede observar, por consiguiente, la presión de la vivencia social se compensa en el guion de esta película con la protección que ofrece el entorno familiar. Mientras esto sucede, la energía que permitiría avanzar y superar los momentos críticos de la experiencia (individual y social) procede de la profundidad de un cerebro que ha censurado su dimensión inconsciente para así totalizar su experiencia como experiencia consciente y supuestamente realista. Pero esta totalización impide que emerjan fisuras, desvíos o conflictos psicológicos e ideológicos que pudieran dar lugar a acciones a su vez conflictivas $o$ de carácter políticamente contestatario. 
Se cumple así la hipótesis crítica planteada por Dorfman y Mattelart en sus pioneros análisis de las historietas del Pato Donald: "Todos los intentos de Disney se basan en la necesidad de que su mundo sea aceptado como natural, es decir, que combine los rasgos de normalidad, regularidad e infantilismo" (Dorfman y Mattelart 1998: 41). La experiencia mental preadolescente (o más bien, en realidad, apta para todos los públicos) se presenta así como naturalizada por la acción de emociones de origen biológico y por tanto universales, tal como defiende el psicólogo estadounidense Paul Ekman, asesor científico de Inside Out (en Latinoamérica titulada Intensa Mente), a pesar de que la comunidad científica discute en términos neuropsicológicos si esta tesis universalista es absolutamente cierta ${ }^{1}$. Desde una perspectiva psicoanalítica, de hecho, se entendería como una censura represiva, castrante, el hecho de reducir los procesos emocionales fundamentalmente al control consciente de un Yo que pierde así vías de liberación creativa y crítica de su fuerza libidinal. El corto-prólogo que se proyecta inmediatamente antes de Del revés, titulado Lava, sitúa sintomáticamente el marco perceptivo en la ensoñación deseante que se establece entre dos volcanes que liberan su fuerza ardiente desde el fondo del mar. Este corto funciona, en fin, como marco o frame para la localización adecuada de la historia subsiguiente en el terreno de la pugna entre consciente e inconsciente, una pugna que finalmente se resolverá por una negación de éste en virtud de una sublimación de aquél.

El poder de los sueños se instaura en Inside Out al precio de representarlos tal como los entiende

Ansede, M. 2016. "El pueblo en el que la sonrisa no significa alegría". El País 19/8/2016. la industria cultural contemporánea. Los sueños pierden así la condición creativa y crítica que forma parte de su elaboración, negándose así hasta qué punto, según concluía la investigación freudiana en La interpretación de los sueños: "en la formación de los sueños interviene también una labor intelectual crítica que no se limita a repetir materiales de los productos oníricos" (Freud 2013: 371). Esta negación es posible gracias a la configuración de una normatividad naturalizada bajo la forma de conducta realista. La figura paterna y el orden familiar actúan aquí como matrices de un sistema cerrado en torno a su propio ideal. Esta predominancia opresiva del Superyo se canaliza así a través de la familia tradicional y de una obsesión ciega por la diversión y la felicidad que debería conducir a una neurosis de insatisfacción creciente. Como sucede con las relaciones interpersonales en la sociedad de consumo, "un sistema que se monta sobre expectativas supone una mutación del Superyo. El Superyo se ha hecho más difuso. El Superyo es el ideal del Yo, es decir, en su realización fáctica. El Yo se obliga, más que nunca, a la extrema docilidad, porque el Superyo se ha hecho prepotente" (Castilla del Pino 1971:122). La docilidad, en suma, podría ser la enseñanza primordial que el espectador aprendería siguiendo la divertida historia de la mente de Riley.

La idealización o sublimación opera aquí como un borrado de las condiciones de opresión, precariedad y vulnerabilidad, que se dan en la vida cotidiana dentro del sistema económico capitalista (y en particular en la crisis de la subjetividad inducida por su particular y asfixiante economía psíquica). El principal mecanismo de sublimación activado por la película quizá provenga justamente del hecho de tratarse de una película de cine. En otras 
palabras, la constante referencia al mundo de los sueños se canaliza mediante la apelación escenográfica al papel del cine en la historia de Riley, es decir, en la diégesis o enunciado del film, a la vez que funciona efectivamente en el lugar de la enunciación/recepción que se activa en la mirada del espectador de la película en la sala de cine o en su propio salón de casa. El aparato fílmico (celebrado como Fábrica de Sueños) interviene tanto dentro como fuera de la película, por decir así, difuminando en la práctica la frontera entre dentro y fuera. Cuando Alegría y su pandilla llegan al pabellón de El Sueño Producciones su entrada en el universo fascinante de las pantallas se celebra como un éxtasis eufórico, como un clímax emocional incomparable, luminoso y celebratorio (imagen 9). Sin embargo, la reproducción de tópicos escénicos y espectaculares en Imaginalandia impide pensar que la actividad de la fantasía "se muestra en el sueño no solamente reproductiva, sino productiva" (Freud 2013: 114). Pero en la escena de Inside Out la entrada en la producción onírica se cosifica mediante la reproducción realista de un multicine deslumbrante, repleto de carteles gigantes, donde las películas se anuncian y estrenan en una sucesión inmediatamente reconocible (imagen 10). En un momento tan intensamente eufórico como éste, la experiencia cinematográfica propia de la sociedad industrializada se presenta como la eutopía par excellence, el lugar propicio para la realización idílica de ese leitmotiv permanente que es aquí el sueño y su capacidad para sublimar (negándola) la crisis individual y colectiva de los sujetos.
Imagen 9. El sueño Producciones (exterior)

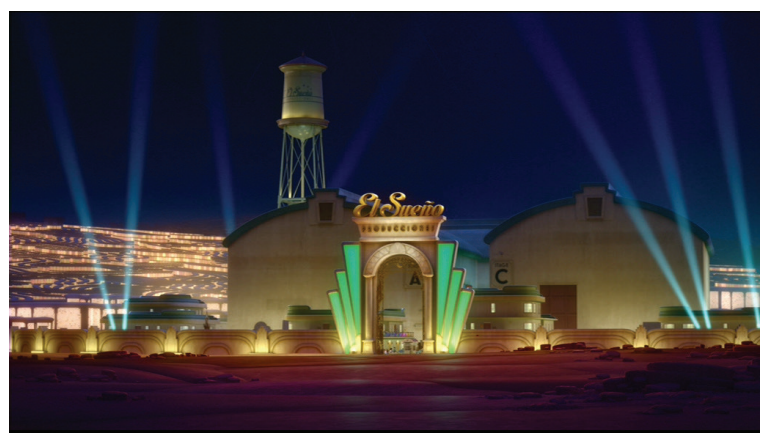

Fuente: Inside Out (Del revés, 2015)

Imagen 10. El Sueño Producciones (interior).

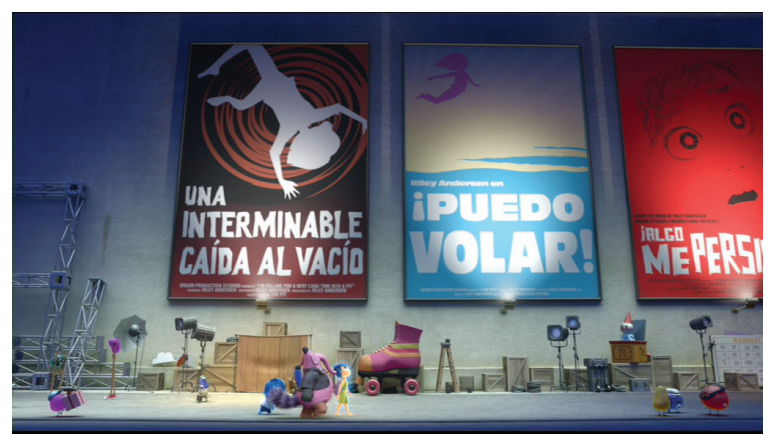

Fuente: Inside Out (Del revés, 2015)

En conclusión, se aprecian en el análisis dos planos de actuación de la estrategia eutópica del film y su función ideológica de reafirmación/ reproducción de la realidad establecida. En un primer nivel, más particular, la película reactiva el afán de Disney por proyectar globalmente "una utopía corporativa" que, lejos de ser inocente, comienza de hecho por el final de cualquier inocencia (Giroux 2001: 49). Esta lógica no sería otra que la de manufacturar la fantasía (Wasko 2001: 5). En un segundo nivel más 
general y más profundo, además, y de manera complementaria a lo anterior, el encaje funcional entre texto audiovisual y contexto social parece confirmar que "el régimen neoliberal presupone las emociones como recursos para incrementar la productividad y el rendimiento. (...) Ser libre significa incluso dejar paso libre a las emociones. El capitalismo de la emoción se sirve de la libertad. Se celebra la emoción como una expresión de la subjetividad libre" (Han 2015: 71). La estrategia de poder neoliberal, concebida como una psicopolítica, explotaría la libertad subjetiva colonizándola en primer lugar para, después, en fin, modularla en una clave de normalidad, realismo y docilidad.

\section{Conclusión}

El espacio fílmico, entendido como síntoma del espacio social, no puede dejar de entrar en relación con el contexto social en que el cine se produce, distribuye y consume. No se trata, de hecho, de una relación pasiva o secundaria sino más bien de una interacción activa, (re) productiva, que influye constantemente en la construcción del imaginario colectivo. Esta influencia es todavía más notoria y pregnante cuando se trata de cine con una poderosa presencia en los circuitos de la cultura masiva, hoy operativos a una escala mundial, por lo que el micro-análisis de algunos textos fílmicos ejemplares puede contribuir a iluminar las tensiones y conflictos más extensos e intensos en el nivel macro-social. El análisis cultural puede así colaborar en la elaboración de perspectivas teóricas y pedagogías críticas intertextuales e interdisciplinares, actualizadas, orientadas a una comprensión compleja de los vínculos entre el imaginario social, la mirada espectatorial y el "deseo capitalista" (Giroux 1996: 74).
La aproximación a la relación concreta entre texto audiovisual y contexto sociohistórico admite, entre otras, la hipótesis de un nexo o ensamblaje ideológico entre subjetividad y orden social, entre mirada y statu quo o, si se quiere, entre cultura y sociedad. En los casos de Los juegos del hambre y Del revés, como en otros similares que podrían abordarse a partir de éstos (como respectivamente sucedería en casos como Divergente (Neil Burger, 2014) o Home (Tim Johnson, 2015), la oscilación entre catástrofe (distopía) y euforia (eutopía) se muestra como un doble juego que desemboca en una misma reafirmación del orden hegemónico. Podría decirse incluso, que el advenimiento de la catástrofe en el subconsciente, vinculado a la situación real de crisis sistémica y expresada en el mainstream cinematográfico post-apocalíptico, funciona a modo de catalizador para la creación de una serie de filmes eutópicos que tratarían de imponer en la conciencia esa noción de felicidad que mantiene fija la mirada del espectador en el marco de los deseos del capitalismo. En ese aspecto, Los Juegos del Hambre constituirían el intento o delirio de proyectar una imagen en la que la euforia de Inside Out, el modo de vida hegemónico, sobreviva aún en un mundo devastado.

Vistas estas películas en el diálogo cultural que suponen, se las puede entender en un régimen bipolar, esquizoide, que va de un extremo emocional a otro, de la alarma apocalíptica al entretenimiento complaciente, del pesimismo cínico a la diversión (presuntamente) inocente... Esta oscilación transversal podría estar funcionando como una doble vía de falsa salida ante los conflictos acuciantes de orden subjetivo y colectivo, psicológico e ideológico, que atraviesan la crisis del modelo social actual. 


\section{Bibliografía}

AAVV. 1992. Sociología de la utopía. Barcelona: Editorial Hacer.

Bauman, Z. 2009. Ética posmoderna. Madrid: Siglo XXI. . 2015. Modernidad y Holocausto. Madrid: Sequitur. . 2017. Retrotopía. Barcelona: Paidós.

Campanella, T. 2018. La ciudad del sol. Madrid: Tecnos.

Castilla del Pino, C. 1971. Psicoanálisis y marxismo. Madrid: Alianza Editorial.

Claeys, G. 2017. Dystopia: A Natural History. Oxford: Oxford University Press.

Claeys, G. y Tower, L. 1999. The Utopia Reader. New York: New York University Press.

Dorfman, A. y Mattelart, A. 1998. Para leer al Pato Donald (Comunicación de masa y colonialismo). México: Siglo XXI.

Freud, S. 2013. La interpretación de los sueños. Madrid: Alianza Editorial.

. 2017. El yo y el ello (y otros escritos de metapsicología).

Madrid: Alianza Editorial.

Giroux, H. 1996. Placeres inquietantes (Aprendiendo la cultura popular). Barcelona: Paidós.

2001. El ratoncito feroz (Disney o el fin de la inocencia).

Madrid: Fundación Germán Sánchez Ruipérez.

Habermas, J. 2008. "La modernidad, un proyecto inacabado".

La posmodernidad. Foster, H. (Ed.). Barcelona: Kairós. 19-36.

Han, B-Ch. 2015. Psicopolítica. Barcelona: Herder.

Horkheimer, M. 1992. "La utopía". Sociología de la utopía.

AAVV. Barcelona: Editorial Hacer. 117-136.

Huxley, A. 2014. Un mundo feliz. Barcelona: Debolsillo.,

Lefebvre, H. 2013. La producción del espacio. Madrid: Capitán Swing.

López-Petit, S. 2009. La movilización global. Breve tratado para atacar la realidad. Madrid: Traficantes de sueños. Lyotard, J. 2000. La condición postmoderna. Madrid: Cátedra. Mannheim, K. 1992. "Utopía". Sociología de la utopía. AAVV. Barcelona: Editorial Hacer. 109-116.

Martel, F. 2011. Cultura mainstream (Cómo nacen los fenómenos de masas). Madrid: Taurus.

Martín-Barbero, J. 2010. De los medios a las mediaciones (Comunicación, cultura y hegemonía). Barcelona: Anthropos.

Méndez-Rubio, A. 2016. "Aprendiendo a mirar: crisis social y crisis espacial en la imagen fílmica". Altre Modernità (Numero Speciale): 15-40.

Milner, J-C. 2010. La arrogancia del presente: miradas sobre una década: 1965-1975. Buenos Aires: Manantial.

Moro, T. 2016. Utopía. Barcelona: Ariel.

Orwell, G. 2018. 1984. Barcelona: Debolsillo.

Rey Segovia, A-C. 2016. Cine distópico y crisis social (El caso de la adaptación cinematográfica de Los Juegos del hambre). Trabajo Fin de Máster / Universitat de València.

Ricoeur, P. 2009. Ideología y utopía. Barcelona: Gedisa.

Sloterdijk, P. 2007. En el mundo interior del capital (Para una teoría filosófica de la globalización). Madrid: Siruela.

Wasko, J. 2001. Understanding Disney. Cambridge: Polity Press.

Wells, H. G. 2000. Una utopía moderna. México DF: Océano / Abraxas.

Zamiatin, E. 2016. Nosotros. Madrid: Hermida.

Zizek, S. 2006. Arriesgar lo imposible (Conversaciones con Glyn Daly). Madrid: Trotta. 2008. En defensa de la intolerancia. Madrid: Sequitur. Madrid: Akal
2009. Primero como tragedia, después como farsa. 